\title{
Role of Tropical Atlantic SST Variability as a Modulator of EI Niño Teleconnections
}

\author{
Yoo-Geun Ham ${ }^{1}$, Mi-Kyung Sung ${ }^{2}$, Soon-II An ${ }^{3}$, Siegfried D. Schubert ${ }^{4}$, and Jong-Seong Kug ${ }^{5}$ \\ ${ }^{1}$ Faculty of Earth Systems and Environmental Sciences, Chonnam National University, Gwangju, Korea \\ ${ }^{2}$ Korea Polar Research Institute, Incheon, Korea \\ ${ }^{3}$ Department of Atmospheric Sciences, Yonsei University, Seoul, Korea \\ ${ }^{4}$ GSFC Global Modeling and Assimilation Office, Greenbelt, Maryland, USA \\ ${ }^{5}$ Korea Institute of Ocean Science and Technology, Ansan, Korea
}

(Manuscript received 14 June 2013; accepted 14 October 2013)

(C) The Korean Meteorological Society and Springer 2014

\begin{abstract}
The present study suggests that the off-equatorial North Atlantic (NATL) SST warming plays a significant role in modulating El Niño teleconnection and its impact on the North Atlantic and European regions. The El Niño events accompanied by NATL SST warming exhibit south-north dipole pattern over the Western Europe to Atlantic, while the ENSO teleconnection pattern without NATL warming exhibits a Rossby wave-like pattern confined over the North Pacific and western Atlantic. Especially, the El Niño events with NATL warming show positive (negative) geopotential-height anomalies over the North Atlantic (Western Europe) which resemble the negative phase of the NAO. Consistently, it is shown using a simple statistical model that NATL SSTA in addition to the tropical Pacific SSTA leads to better prediction on regional climate variation over the North Atlantic and European regions. This role of NATL SST on ENSO teleconnection is also validated and discussed in a long term simulation of coupled global circulation model (CGCM).
\end{abstract}

Key words: ENSO, NAO, teleconnection, North Tropical Atlantic

\section{Introduction}

In spite of its confined region of origin over the tropical Pacific, El Niño has world-wide impacts on global climate and weather events such as droughts, floods, cold and heat waves. During last few decades, numerous studies have investigated the impact of ENSO on the worldwide climate as well as the underlying physics of the phenomenon (e.g., Rasmusson and Carpenter, 1982; Kiladis and Diaz, 1989; Ropelewski and Halpert, 1989; Trenberth and Hurrell, 1994; Halpert and Ropelewski, 1992; Trenberth et al., 1998; An et al., 2007; Kug et al., 2010a).

In northern extra-tropical areas, the response to the anomalous tropical forcing associated with ENSO primarily occurs over the North Pacific and North America (Horel and Wallace, 1981; Hoskins and Karoly, 1981; Held and Kang, 1987; Alexander, 1990, 1992a, b; Lau and Nath, 1996). Held and Kang (1987) showed that the tropical divergence forcing can reproduce the extratropical wave train during ENSO using a

Corresponding Author: Jong-Seong Kug, Korean Institute of Ocean Science and Technology, 787 Haean-ro, Sangnok-gu, Ansan 426-744, Korea.

E-mail : jskug1@gmail.com simple barotropic model. Similarly, Lau and Nath (1996) showed that SST anomalies (SSTA) over the tropical Pacific (i.e., Tropical Ocean-Global Atmosphere (TOGA) experiment) successfully simulate observed atmospheric anomalies associated with ENSO over the North Pacific/America using GFDL atmospheric general circulation model (AGCM). They also argued that the atmospheric responses to the tropical forcing associated with ENSO generate the significant SST anomalies over the North Pacific through the air-sea interactions.

Together with the responses over the Pacific/America, the impact of ENSO over the North Atlantic and European regions has also been investigated by many researchers (van Loon and Madden, 1981; Rogers, 1984; Fraedrich, 1990; Huang et al., 1998; van Oldenborgh et al., 2000; Pozo-Vazquez et al., 2001). However, the statistical relationship seems to be not simple, with the results depending on the data period and season. For example, Bronnimann et al. (2007) suggested that El Niño events tend to be accompanied in late winter by a negative NAO index. On the other hand, Pozo-Vazquez et al. (2001) and Fraedrich (1990) found that there is no statistically significant circulation patterns over the North Atlantic region associated with El Niño events, while during cold events a statistically significant anomaly pattern resembling the positive phase of the North Atlantic oscillation (NAO) was found.

This lack of agreement about the impact of the ENSO on the North Atlantic climate variability reflects a lack of understanding of the mechanism by which ENSO impacts climate variability over the North Atlantic. For example, even though Ropelewski and Halpert (1987) found an evidence for ENSOrelated precipitation variability in northern Africa and southern Europe, they pointed out that the ENSO relationships in these regions are difficult to understand or attribute to any of the known ENSO related atmospheric circulation changes. In addition, the local interactions between atmospheric eddy activity and SST over the Atlantic might cause the weak connection to the ENSO. For example, the NAO is known to be mainly derived by the atmospheric eddy activity (Barnett, 1985; Kitoh et al., 1996; Osborn et al., 1999; Robertson et al., 2000; Sutton et al., 2001; Peng et al., 2003; Pan, 2005). The NAO-related surface wind and related latent heat flux can induce the tropical and local SST variability (Czaja et al., 2002), then, it 
can reinforces the NAO-like atmospheric variability (Watanabe and Kimoto, 1999; Okumura et al., 2001). This two-way feedback between NAO and local SST variability can prohibit the connection between the ENSO and North Atlantic climate variability.

To improve the understanding in ENSO teleconnection over the North Atlantic and European region, this study investigates which factor during El Niño can affect the North Atlantic climate variability in addition to the tropical Pacific SSTA. Especially, we investigate a role of the off-equatorial North Atlantic (NATL) SST anomalies related to the ENSO, because of its linkage to both North Atlantic variability (Watanabe and Kimoto, 1999; Okumura et al., 2001) and the ENSO (Curtis and Hastenrath, 1995; Enfield and Mayer, 1997; Klein et al., 1999; Saravanan and Chang, 2000; Alexander and Scott, 2002; Chiang and Sobel, 2002; Czaja et al., 2002). It means that the NATL SSTA can bridge the ENSO and North Atlantic climate variability.

The linkage between ENSO and the tropical Atlantic SST has been investigated by many researchers. It is reported that the NATL SSTA is correlated to the ENSO with few month's time lags. The ENSO-related SST anomalies over the tropical Atlantic can be induced by modifying surface wind anomalies (Curtis and Hastenrath, 1995; Enfield and Mayer, 1997; Saravanan and Chang, 2000; Alexander and Scott, 2002). During El Niño the reduction of latent heat due to anomalous westerly over the equatorial North Atlantic leads to ocean surface warming. The other possible explanation is given by Chiang and Lintner (2002) that the tropospheric warming during the El Niño is essential for the remote SST response. That is, El Niño releases heat from the ocean into the atmosphere which distributed to the rest of the tropical free troposphere through the equatorial waveguide. As the convective activity links the boundary layer to free atmosphere, therefore, the tropospheric warming must also warm with the boundary layer. The heating also results in an increase in the tropical tropospheric water vapor content, thereby increasing the clear-sky downwelling longwave radiation to heat the ocean. Especially, the remote ENSO impact over the tropical Atlantic is robust in the NATL region, because the atmospheric bridge mechanism is cancelled by the opposite influence of oceanic processes over the South tropical Atlantic (Chang et al., 2006). Recently, it is argued that the Atlantic SST in turn affects Pacific ENSO events with 6 month time lag (RodriguezFonseca et al., 2009; Wang et al., 2011).

This paper is organized as follows. Section 2 provides a description of the data used in this study. The role of NATL SST anomalies during the ENSO on the teleconnection patterns over the North Atlantic and European region using observational output is investigated in Section 3, and Section 4 supports the observational finding using the long-term integration of CGCM output. The summary and discussion are presented in Section 5.

\section{Data sets}

The monthly-mean wind, geopotential height, and surface temperature data from 1948 to 2007 are obtained from the National Centers for Environmental Prediction/National Center for Atmospheric Research reanalysis (NCEP/NCAR, Kalnay et al., 1996). SSTs are from the National Oceanic and Atmospheric Administration (NOAA) Extended Reconstructed Sea Surface Temperatures (ERSST, Smith and Reynolds, 2004). Note that all data are de-trended. In this study, we focus on the boreal winter season when the ENSO teleconnection is prominent (Alexander and Scott, 2002). Especially, the atmospheric response during the late winter (i.e., JF season) are analyzed because it is known that the remote impact of El Niño differs over the Atlantic markedly between early and late winter over the North America and the North Atlantic regions (Montroy, 1997; Montroy et al., 1998; Wang and Fu, 2000; Moron and Gouirand, 2003). For Nino3 and NATL SSTA, we used same JF season due to the fast timescale of the atmospheric teleconnection to the SST forcing.

Because the observational data can be limited to show a robust result due to small samples, this study also analyzed long-term (500-yr) climate simulations with the GFDL CM2.1 coupled model to examine how well this model simulates the observed relationship. Reasonable mimicking of the model will support a robustness of the observational findings. In this study, a preindustrial simulation is used with fixed values for atmospheric composition, land cover, and insolation based on data for the year 1860. The ocean component of CM2.1 is based on Modular Ocean Model version 4 (MOM4) code. The resolution is 50 vertical levels and a $1^{\circ} \times 1^{\circ}$ horizontal grid telescoping to $1 / 3^{\circ}$ meridional spacing near the equator. The vertical grid spacing is a constant $10 \mathrm{~m}$ in the top $220 \mathrm{~m}$. The atmospheric component is the GFDL atmospheric model. The resolution is 24 vertical levels and $2^{\circ}$ latitude by $2.5^{\circ}$ longitude grid spacing. The dynamic core is based on a finite volume (Lin, 2004). Air-sea fluxes are computed based on 1-h intervals. For a detailed model description, refer to Delworth et al. (2006) or Wittenberg et al. (2006).

\section{Observed characteristics}

\section{a. Teleconnection pattern}

Figure 1 shows a composite map of the late winter-mean (JF) 500 hpa geopotential height (Z500) anomalies and JF SSTA during the El Niño. The El Niño events are defined as a case when the Nino3 index during JF is larger than its 0.5 standard deviation (std). The 13 El Niño events are selected and used for the composites from the 60 years (1948-2007) of observation. For all the composite analyses, significant test is performed using the student t-test based on the temporal standard deviation. That is two-tailed t-test for which the distribution of the test statistic under the null hypothesis can be 


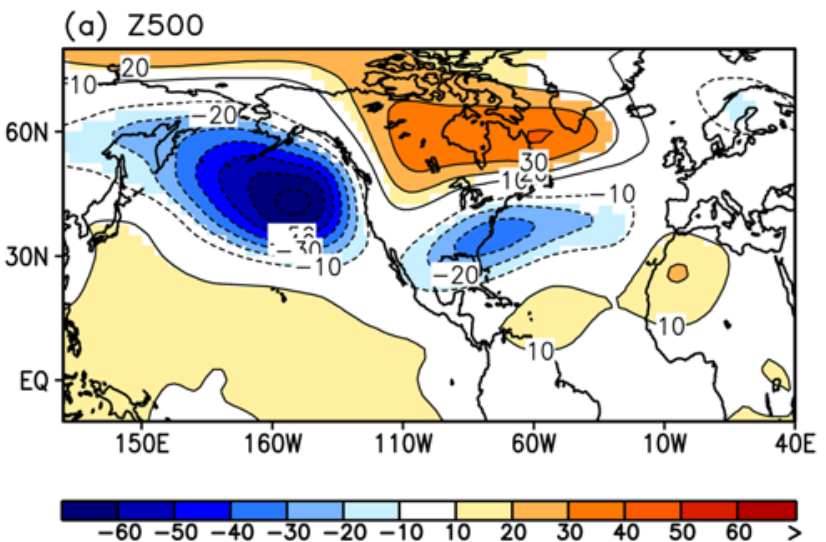

(b) SSTA

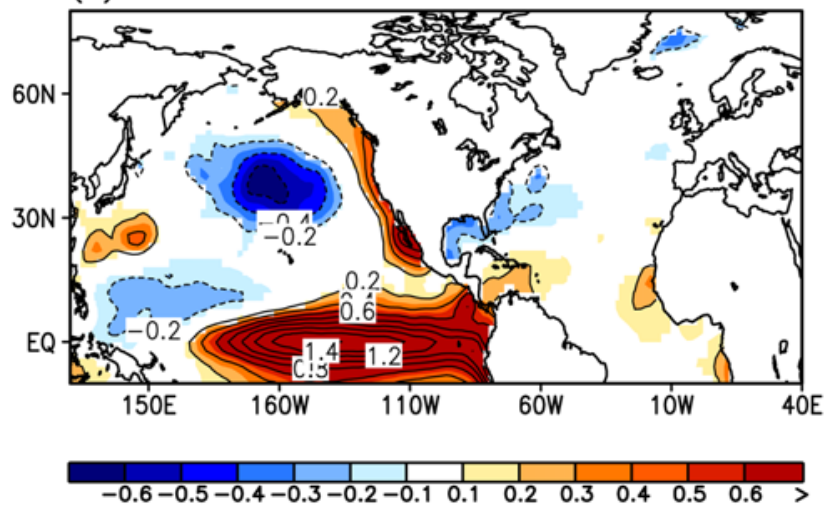

Fig. 1. Composite map of Jan. to Feb. (JF) SST, and 500 hpa geopotential height (Z500) anomalies during El Niño. Note that the regions where significance level is over $99 \%$ are shaded.

approximated by a t-distribution.

The observational data shows a typical response in which a cyclonic anomaly develops over the North Pacific, associated with an intensification and eastward shift of the Aleutian Low. In conjunction with the North Pacific circulation, there is also a zonally elongated anomalous anticyclonic flow over Canada and western Atlantic, and anomalous cyclonic flow over the southeastern United States extending into the subtropical Atlantic. This north/south dipole response occurs primarily over America but has some extension into the western Atlantic. Though it is known as a typical El Niño teleconnection

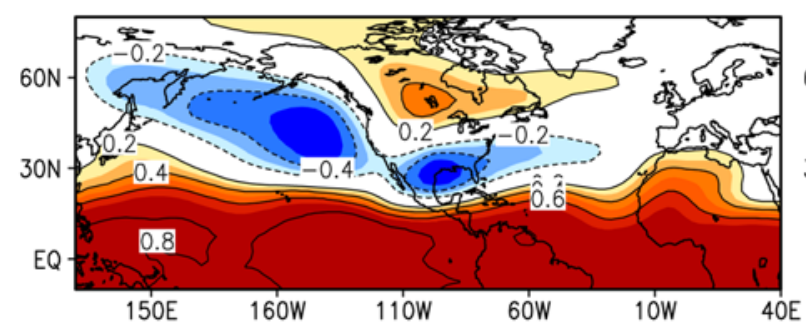

patterns, it is still unclear how tropical Pacific forcing can generate this particular teleconnection pattern over extratropics. The Rossby wave responses to tropical diabatic heating (Hoskins and Karoly, 1981; Held and Kang, 1987) may not be enough to explain this telelconnection pattern.

The SSTA exhibits consistent signals as shown in Fig. $1 \mathrm{~b}$. There is negative SSTA over the central North Pacific, while there is positive SSTA over the far-eastern North Pacific. Lau and Nath $(1996,2001)$ showed that anticyclonic flow over the North Pacific plays an important role in producing local SSTA by changing surface heat fluxes. The negative SST anomalies over the central North-Pacific are generated by increasing latent heat fluxes due to intensified wind speed. They also showed that decreased wind speed leads to positive SST anomalies over the far-eastern North Pacific. In contrast to the Pacific region, SSTA over the Atlantic Ocean are relatively weak and confined over the western Atlantic. The El Niño related SSTA over the Atlantic Ocean are characterized by a dipole pattern with positive SST anomalies over the offequatorial region and negative SSTA over the extratropics. This sign of the SSTA over the western Atlantic is dynamically consistent with the changes in wind speed associated with the local cyclonic flow. For example, the southwesterly at southeastern edge of cyclonic flow off the eastern coast of South America leads to a reduction in wind speed over the offequatorial North Atlantic, which causes the SST warming (not shown).

Next, we compare the teleconnection pattern related to the off-equatorial North Atlantic SST. In this study, an index of the off-equatorial North Atlantic SST anomalies is defined as the area-averaged SST anomalies over $90^{\circ} \mathrm{W}-0^{\circ} \mathrm{E}, 0^{\circ} \mathrm{N}-15^{\circ} \mathrm{N}$ during $\mathrm{JF}$ season. For simplicity, hereafter this index is called the NATL index. Figure 2 shows the map of correlations between the JF Z500 anomalies, and both JF Nino3 and NATL indices. The strong positive correlation over the equatorial band is related to the basin-wide warming during the El Niño (Chiang and Lintner, 2005). Similar in pattern to the El Niño composite in Fig. 1, Nino3-related pattern shows robust correlations over the Pacific-American region. The dipole pattern which is similar to the El Niño composite (Fig. 1a) is also shown, however, it is confined over the America and Canada and that over the western Atlantic becomes weaker.
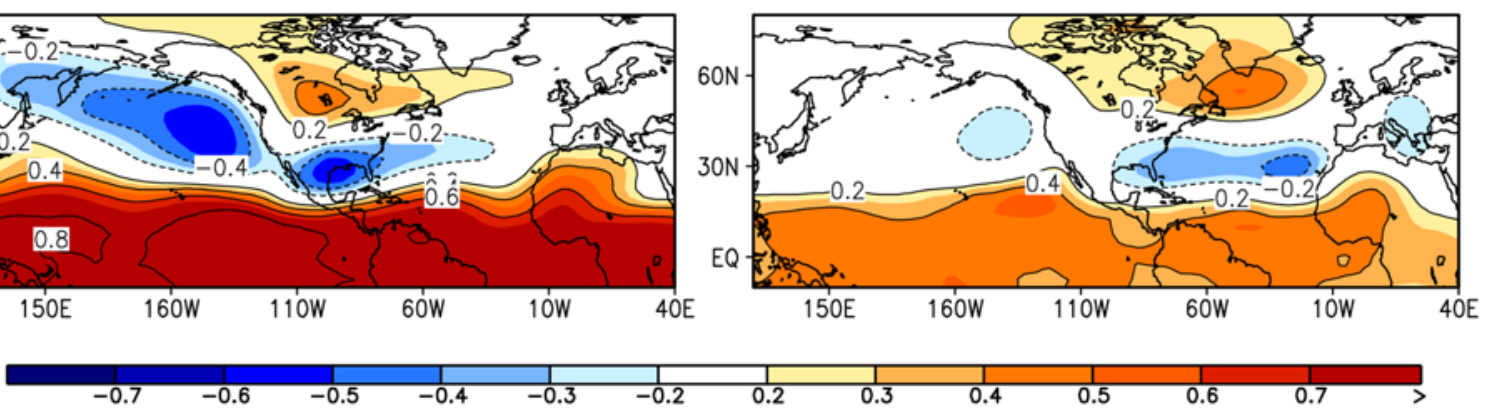

Fig. 2. Correlation map between JF Z500 anomalies, and (a) JF Nino3, and (b) JF NATL indices using observations. 
(a) PCOR (NINO3,Z500)

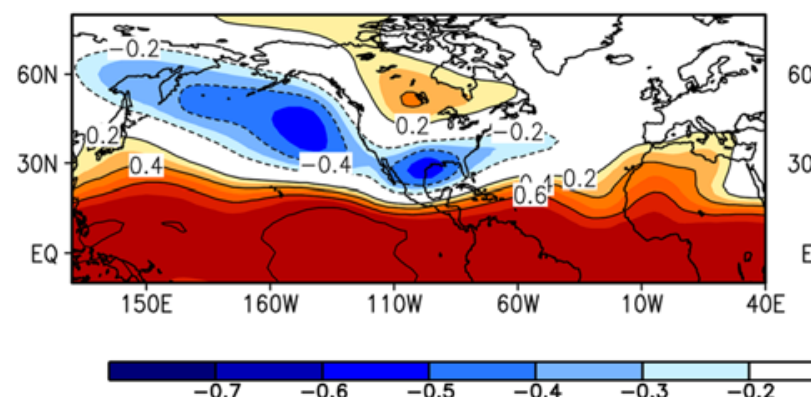

(b) PCOR (NATL,Z500)

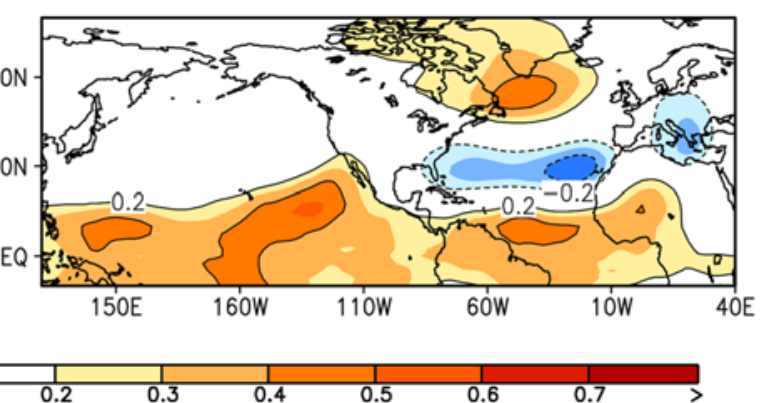

Fig. 3. Partial correlation coefficients of the JF Z500 anomalies on (a) JF Nino3 index, and (b) JF NATL index, after removing the effect of the other. In partial correlation map between Nino3 (NATL) index and Z500 anomalies, the effect of NATL (Nino3) SST anomalies is statistically excluded.

At the first glance, the overall pattern related to NATL index is similar to that to NINO3 SST. For example, there is positive correlation over the equatorial band. In addition, negative Z500 over the North Pacific, and dipole pattern over the AmericaCanada is also revealed. It is because there is a significant correlation between Nino3 and NATL index. For example, the correlation coefficient between the Nino3 index and the NATL index is 0.41 based on 60 years of observations. However, in more detail, there are considerable differences between Nino3related and NATL-related Z500 anomalies. First, the NATLrelated signal is more robust over the Atlantic. For example, the signal over the North Pacific is only shown at the far-eastern North Pacific, and the dipole structure over the North Atlantic extends to the east. As the dipole pattern is expanded to the eastern Atlantic, there can be stronger impacts on the Atlantic and Western Europe. The NATL-related fields shows weak negative Z500 anomaly over the Western Europe, which is consistent with Wang et al. (2010). Note that it is consistent with several previous studies to examine the role of SST forcing over the tropical Atlantic regions (Watanabe and Kimoto, 1999; Okumura et al., 2001).

Even though this correlation map provides rough clues about the role of Pacific and NATL SSTA, it is worthwhile to clarify effects of the Pacific and the Atlantic SST forcing separately because of the high correlation between two indices. Therefore, we introduce partial correlation analysis to separate the impact of NATL from the Nino3 index, and vice versa (Cohen and Cohen, 1983). With this method, influence of Nino3 (NATL) in Z500 anomaly is removed to examine the sole role of NATL (Nino3) index. Kug and Kang (2006) used this method in order to show characteristics of the basin-wide Indian Ocean SSTA, which is not introduced by ENSO.

Figure 3 shows the partial correlation of the JF Z500 anomalies with the JF Nino3 index, and with the JF NATL index, after removing the effect of the other. For example, Fig. $3 \mathrm{a}$ shows a relation between the Nino3 SST and Z500 anomalies, after removing the effect of NATL. Over the North Pacific, the Z500 response over the North Pacific is quite similar to that in Fig. 2a, indicating that the response is independent of NATL SST forcing. However, over the Atlantic, the magnitude of the dipole pattern is much weaker than that in the conventional correlation map as shown in Fig. 2a. For example, partial correlation map shows dipole Z500 anomalies is nearly zero over the Atlantic, while it is extended to the midAtlantic in conventional correlation map (e.g., Figs. 2a and 3a). This implies that the dipole pattern over the Atlantic in Fig. 2a is due to the correlation between the ENSO and the NATL.

On the other hand, the partial correlation map between NATL index and Z500 anomalies shows similar spatial pattern over the North Atlantic to the conventional correlation map with stronger amplitude. There is still dipole structure, exhibiting positive Z500 anomalies over the North Atlantic and negative anomalies over the subtropics. In addition, the negative Z500 anomalies over the Western Europe are commonly shown both in Figs. $2 \mathrm{~b}$ and $3 \mathrm{~b}$, implying that the climate variability over the North Atlantic is strongly determined by the NATL SSTA rather than the Nino3 index. It also implies that NATL SSTA plays a significant role in modulating El Niño teleconnection and its impact on the North Atlantic and the European regions. This results is also consistent with that in Wang et al. (2010) that the widening of the Atlantic warm pool (AWP) induce the barotropic anticyclonic response over the North Atlantic between $40-70^{\circ} \mathrm{N}$, even though their model results seem to be shifted to the west compared to this study (see their Fig. 11 or 12). It might be due to the fact that their AWP index explains a variability over the western Atlantic, while the NATL index represents variability over the whole off-equatorial Atlantic.

Watanabe and Kimoto (1999) argued that the transient eddy can do a substantial role on driving the NAO-like atmospheric response to the tropical Atlantic SST. This study is supported by the others that the transient eddy process modulates the response by the tropical Atlantic heating and ultimately determines the growth of NAO-like response (Terray and Cassou, 2002; Kug and Jin, 2009; Ren et al., 2009; Kug et al., 2010b). Based on these earlier studies, the eddy process might be crucial for the NATL SSTA to link to the NAO-like response.

Figure 4 shows the partial correlation map of SSTA, which show more distinct difference between the relations with Nino3 and NATL. The partial correlation of Nino3 shows 
(a) PCOR (NINO3,SSTA)

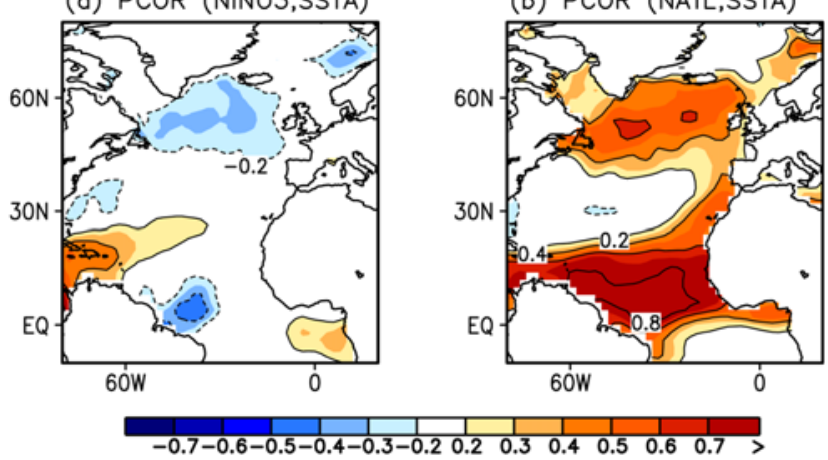

Fig. 4. Partial correlation coefficients of the JF SST anomalies on (a) JF Nino3 index, and (b) JF NATL index.

negative values over equatorial western Atlantic, and North Atlantic over $40-60^{\circ} \mathrm{N}$, while positive values are between $15-$ $30^{\circ} \mathrm{N}$. On the contrary to the Pacific SSTA-related map, the partial correlation of NATL shows almost opposite structure. In addition to the positive SST over the off-equatorial region with the aids of auto-correlation, it is interesting that there is strong positive correlation over the North Atlantic. The location of this positive correlation over the North Atlantic is overlapped with the negative correlation in partial correlation map of Nino3 (Fig. 4a), which implies that there can be cancellation effect in SSTA between the Pacific and NATL SSTA warming. This positive SSTA signal over the North Atlantic can enhance the local high as shown in Fig. 3b, in turn, the anticyclonic flow related to the local high can reinforce the warm SSTA through Ekman transport. It implies that the local air-sea interaction may amplify the remote effect from ENSO on North Atlantic.

In short, there are some points for the role of NATL SSTA on ENSO teleconnection. The Nino3-related Z500 and SSTA over the Atlantic are quite dependent on the existence of NATL SSTA. For example, partial correlation map of Nino3 (Fig. 3a) is different from the conventional correlation map (Fig. 2a) especially over the Atlantic. Especially, the dipole response over the Atlantic, which resembles the negative phase of the NAO, is only shown when the ENSO is accompanied by the NATL index.

In order to further support these findings from the partial correlation, we performed a composite analysis to separate the impact of NATL from ENSO. Here, the 'El Niño only' composite is defined as the composite of cases whose Nino3 index is greater than its $0.5 \mathrm{std}$, and the NATL index is smaller than its 0.5 std. To consider the opposite phase, we select the 'La Niña only' case whose Nino3 index is smaller than its $-0.5 \mathrm{std}$, and the NATL index is greater than its $-0.5 \mathrm{std}$, then the 'ENSO only' case is defined as 'El Niño only' - 'La Niña only' cases divided by 2 . The 'NATL only' composite is defined similarly using the 'Positive NATL only' composite when the NATL index is greater than $0.5 \mathrm{std}$, and the magnitude of the Nino3 index is smaller than its $0.5 \mathrm{std}$, and 'Negative NATL only' composite. And, 'ENSO + NATL' composite is defined similarly using the 'El Niño + Positive NATL' composite of those years when both the Nino3 and NATL index is greater than $0.5 \mathrm{std}$, and 'La Niña + Negative NATL' case. The number of cases in each composite is summarized in Table 1.

Figure 5 shows the Z500 and SSTA composite maps. Similar to the partial correlation map as shown in Figs. 3 and 4 , the Z500 anomalies of the 'ENSO only' composite does not resemble NAO. Instead, 'ENSO only' composite resembles the Rossby wave-like patterns with negative Z500 anomalies over the North Atlantic, and positive anomalies over the midlatitude Atlantic. On the other hand, in 'NATL only' case, the Z500 anomalies shows positive sign in the North Atlantic, and negative sign in the mid-latitude Atlantic, indicating the Z500 responses to Pacific SSTA is dramatically different from that to NATL SSTA. In 'ENSO + NATL' case, the overall pattern is similar to the response during the El Niño in Fig. 1a, even though the dipole responses over the America extend to the east. This eastward extension can be explained by the positive Z500 anomalies over the eastern Canada in 'ENSO only' composite, therefore, responses in 'ENSO + NATL' case can be explained by a linear combination of the responses in 'ENSO only' and 'NATL only' case to a large extent. Overall, the response over the north Pacific in 'ENSO + NATL' composite resembles that in 'ENSO only' composite, while, over the North Atlantic and Western Europe, the responses much resemble that in 'NATL' case. The positive Z500 anomaly is over the North Atlantic at $40-60^{\circ} \mathrm{N}$, and there is negative anomaly over the mid-latitude Western Europe both in 'ENSO + NATL' and 'Positive NATL'. This implies that the NATL SSTA more

Table 1. The number of selected years of each composite. Note that the Nino3 (NATL) index is defined as SSTA over $150-90^{\circ} \mathrm{W}, 5^{\circ} \mathrm{S}-5^{\circ} \mathrm{N}\left(90^{\circ} \mathrm{W}-\right.$ $20^{\circ} \mathrm{E}, 0-15^{\circ} \mathrm{N}$ ) both for observation and model outputs.

\begin{tabular}{ccc}
\hline & Observations (criteria $=0.5$ std) & GFDL CM2.1 $(0.5$ std $<$ criteria $<1.5$ std $)$ \\
\hline EI Niño (Nino3 $>$ criteria) & 13 & 81 \\
EI Niño only (Nino3 $>$ criteria, NATL $<$ criteria) & 8 & 45 \\
Positive NATL only (Nino3 $<$ criteria, NATL > criteria) & 10 & 68 \\
EI Niño + Positive NATL (Nino3 > criteria, NATL > criteria) & 5 & 27 \\
La Niña & 16 & 132 \\
La Niña only & 8 & 63 \\
Negative NATL only & 12 & 65 \\
La Niña + Negative NATL & 8 & 50
\end{tabular}


Z500

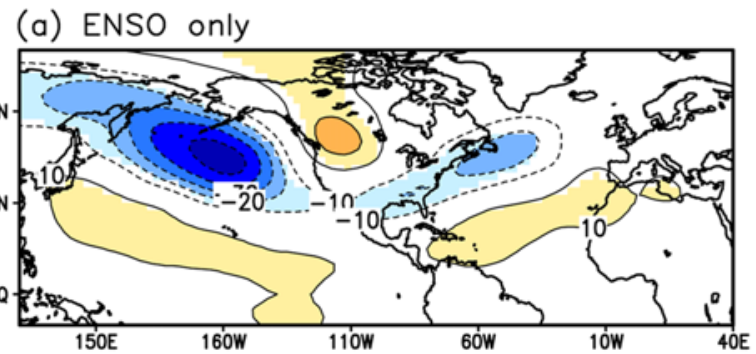

(c) NATL only

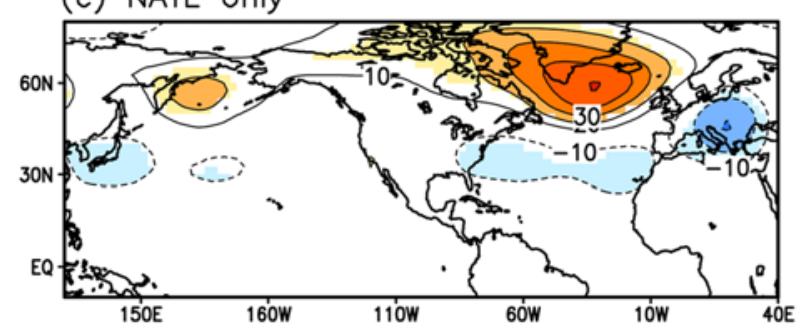

(e) ENSO + NATL
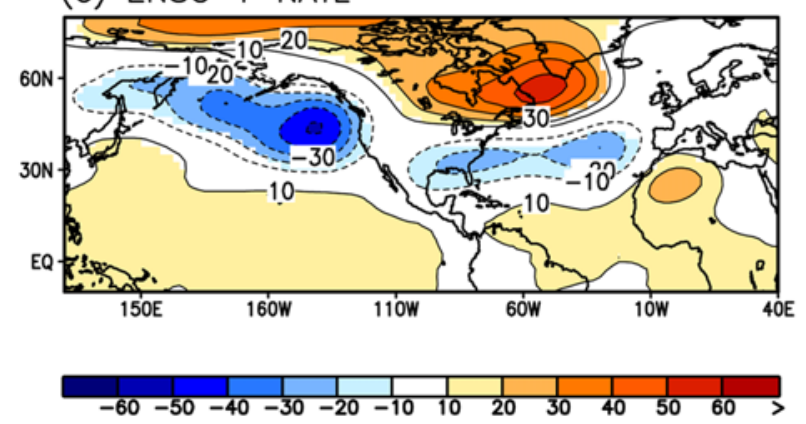

SSTA

(b) ENSO only

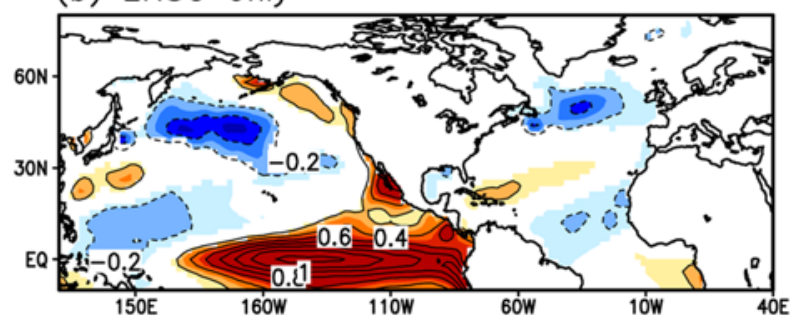

(d) NATL only

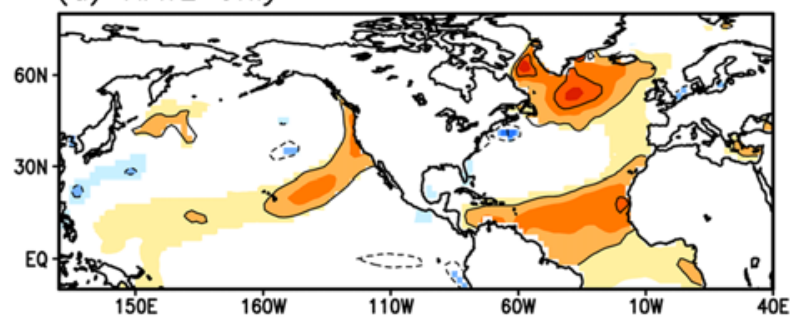

(f) ENSO + NATL
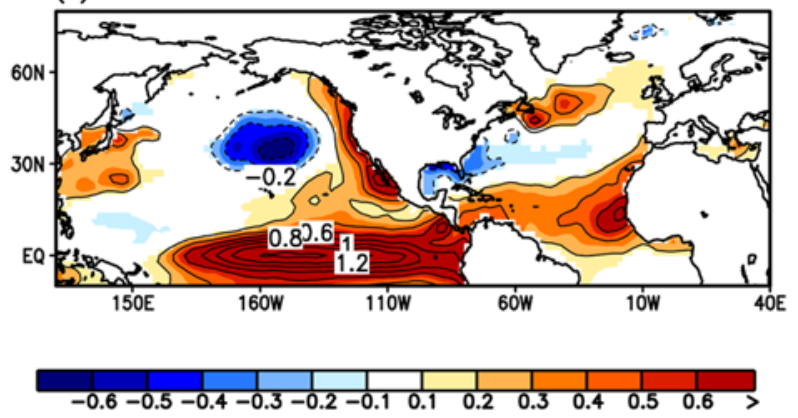

Fig. 5. JF Z500 (left panel) and JF SSTA (right panel) composite map of 'ENSO only', and 'NATL only', and 'ENSO + NATL' cases in observations. Note that the regions where significance level is over $99 \%$ are shaded.

effectively affect climate variability over the North Atlantic and the Western Europe than the ENSO-related Pacific SSTA.

The SSTA in 'ENSO only' also confirms the finding from the partial correlation map shown in Fig. 4a. That is, there are negative SST anomalies just north of the equatorial Atlantic and just south of Greenland. On the other hand, in the 'NATL only' composite, there are two positive centers over the offequatorial and the North Atlantic, and one weak negative center over the mid-latitudinal Atlantic. Siegfried et al. (2009) mentioned that those tripolar SST pattern over the Northern Atlantic is related to the Atlantic multidecadal oscillation (AMO). Also, the ENSO-independent NATL variability is also possibly linked to the dipole mode reported in Moura and Shukla (1981), Servain and Legler (1986), and Servain (1991). Overall, the SST signal over the Atlantic ocean in 'ENSO only' and that in the 'NATL only' composite tend to be opposite in sign, which is consistent with Fig. 4 using partial correlation. When we compare the SSTA response in 'ENSO + NATL' to that in 'ENSO only' case, it is clear that there is considerable difference over the Atlantic. Being opposite to the SSTA in 'ENSO only' case, there is negative, and positive
SSTA over mid-latitude, and the North Atlantic, respectively. Instead, the SST signals over the North Atlantic in 'ENSO + NATL' composite is similar to that in 'NATL only' case, even though the positive SST over the North Atlantic is weaker. It is possibly due to the negative SSTA over the North Atlantic in 'ENSO only' composite.

While this study emphasizes the role of NATL SSTA on the North Atlantic atmospheric variability, there is still a casualty issue that the NATL SSTA is forced by the NAO-like atmospheric response. According to the previous studies, NATL SSTA is generated by the NAO-induced atmospheric circulation (Frankignoul and Hasselmann, 1977). They showed that the surface wind response to the NAO modulates the latent heat flux and the tropical Atlantic SSTA, therefore, there is clear leading role of NAO to tropical Atlantic SSTA. In those cases, the NAO variability tends to lead that of tropical Atlantic SSTA (Frankignoul and Hasselmann, 1977; Czaja et al., 2002; $\mathrm{Wu}$ and Liu, 2002). However, we also found that the relationship between ENSO-related NATL and NAO-like atmospheric variability is enhanced when NATL SSTA leads the atmospheric response. That is, the impact of JF NATL SSTA on 


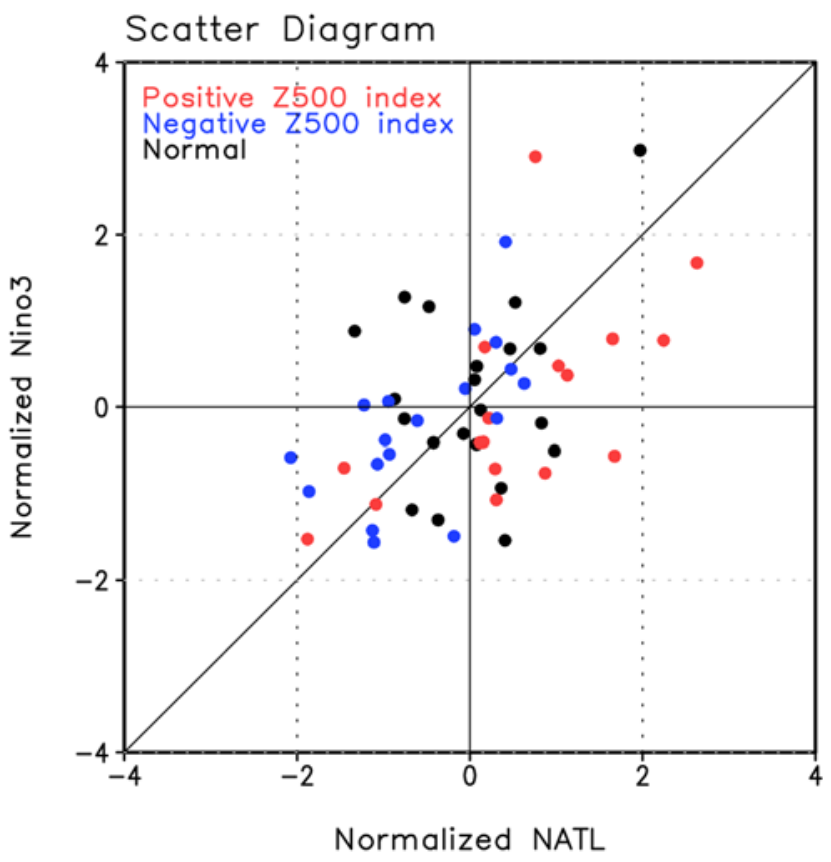

Fig. 6. The scatter diagram between the normalized NATL, and Nino3 magnitude. North Atlantic Z500 index is defined as a area averagedvalue of $\mathrm{Z} 500$ anomalies over North Atlantic regions $\left(80^{\circ} \mathrm{W}-30^{\circ} \mathrm{W}\right.$, $50^{\circ} \mathrm{N}-60^{\circ} \mathrm{N}$ ), then red (blue) dots denotes the events when the intensity of North Atlantic Z500 index is larger (smaller) than $0.5(-0.5)$ standard deviations. In addition, black dots denote the events when the intensity of North Atlantic Z500 index is between -0.5 and 0.5 standard deviations.

Z500 anomaly over the North Atlantic is stronger when SSTA leads Z500 (i.e., JF SSTA and FM Z500) than the Z500 response when SSTA lags Z500 (i.e., JF SSTA and DJ Z500) (not shown). It supports our notions that the NATL SSTA can induce the NAO-like atmospheric response, implying there is two-way interaction between NAO-like circulation and NATL SSTA (Rodwell et al., 1999).

To investigate the different impact of NATL index from El Niño -related Pacific forcing over the Atlantic in more detail, we defined a North Atlantic Z500 index as an area average of Z500 anomalies over the North Atlantic $\left(80^{\circ} \mathrm{W}-30^{\circ} \mathrm{W}, 50^{\circ} \mathrm{N}-\right.$ $\left.60^{\circ} \mathrm{N}\right)$. Then, the intensity of the North Atlantic Z500 index with respect to the normalized NATL and Nino3 indices are shown in Fig. 6. It is likely that the sign of Z500 index is determined by NATL rather than Nino3. For example, $82 \%$ of the positive Z500 index is coincident with positive NATL, while only $41 \%$ of the positive Nino3 index is with positive Z500 index. Similarly, 64\% of negative Z500 index is occurred with negative NATL index, while $42 \%$ of negative Z500 index is with negative Nino3 index. It means that the sign of Nino3 index is less relevant to that of Z500 index. Interestingly, the sign of the North Atlantic Z500 index is likely to be negative (e.g., blue circle) when the Nino3 index is stronger than the NATL index (12 cases among total 17 cases). On the other hand, the North Atlantic Z500 index tends to be positive (e.g., red circle) when the NATL index is stronger than Nino3 index
(13 among total 18 cases). This means that the sign of Z500 anomaly over the North Atlantic is determined by the relative strength of Nino3 and NATL index. This further supports our argument that the impact of Pacific SST forcing on the North Atlantic climate variability tends to be opposite to that of the off-equatorial Atlantic SST forcing.

\section{b. Surface temperature and precipitation}

The anomalous circulation pattern leads to anomalous local surface climate over North America and Europe. Since we showed the ENSO teleconnection pattern is considerably modulated by the NATL SSTA, one may expect different ENSO impact depending on state of NATL SST. Figure 7 shows the surface temperature and precipitation anomaly in each composite. During the 'ENSO' events (e.g., cases of Nino $3>0.5$ std minus cases of Nino $3<-0.5$ std divided by 2 ), there are negative surface temperature anomalies over the southern United States and positive anomalies over western Alaska. This south-north dipole pattern over the America is also observed in the precipitation composite. However, over the European region, the signal in both surface temperature and precipitation is quite weak.

On the contrary to the south-north dipole pattern in 'ENSO' composite, the positive anomalies over the northern America are far confined to the west in 'ENSO only' composite. And, there is slight negative surface temperature anomaly over the west of the Greenland. The spatial pattern of precipitation anomaly is similar to the 'ENSO' case, but the negative anomaly over the eastern Canada is enhanced with aids of the local cold surface temperature. Over the Western Europe, there is weak positive signal in surface temperature, but the magnitude is quite weak.

In the 'NATL only' composite, the surface temperature and precipitation anomaly is dramatically different from that of the 'ENSO only' composite. For example, in the 'NATL only' composite, there are strong positive surface temperature anomalies over the north-eastern North America. The precipitation composite is also opposite over the America consistent with previous study (Enfield, 1996). Over the Western Europe, there is significant cold surface temperature anomaly.

It is striking that the signal in the 'ENSO + NATL' case is significantly different from that of the 'ENSO only' case, even though southern North America shows consistent sign in surface temperature and precipitation. Instead, the composite pattern in the 'ENSO + NATL' is similar to that in 'NATL only' case over the North America, Canada, and Western Europe. In 'ENSO + NATL' composite, positive surface temperature anomaly over the eastern part of North America is shown similar to that in 'NATL only' composite. In addition, there are significant negative surface temperature anomalies over northern Europe both in 'NATL only' and 'ENSO + NATL'. Similarly, precipitation anomaly in 'El Niño + Positive NATL' case is similar to that in 'positive NATL only' over the Europe. It clearly shows the NATL warming plays a significant role in 
TS

\section{(a) ENSO}

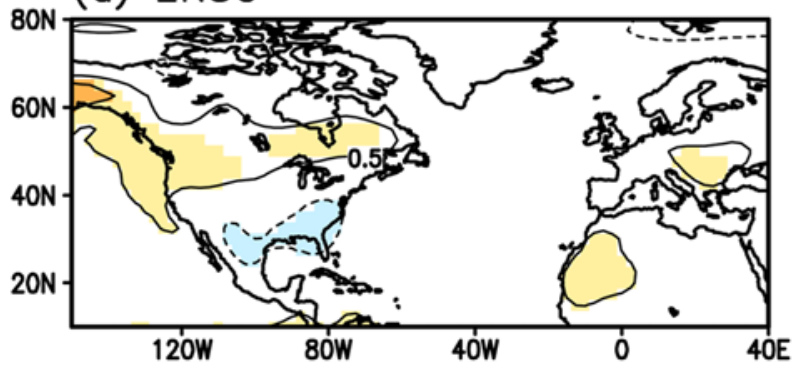

(c) ENSO only

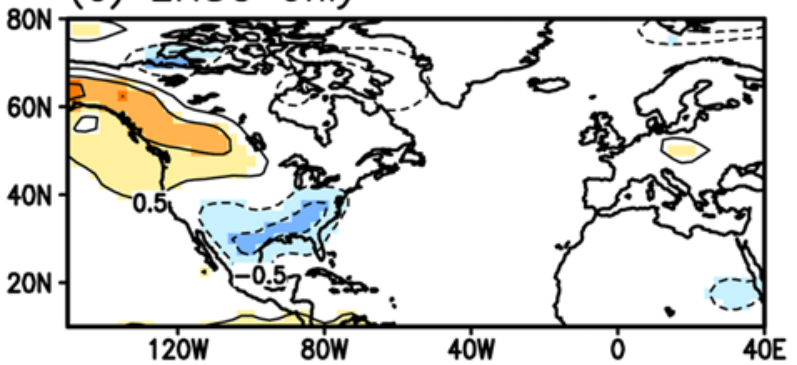

(e) NATL only

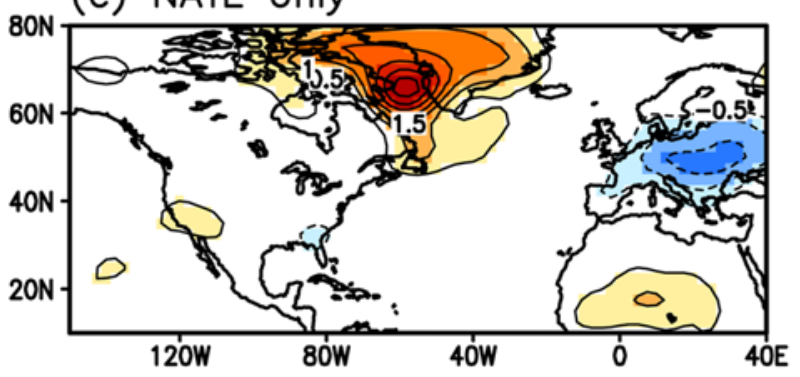

(g) ENSO + NATL
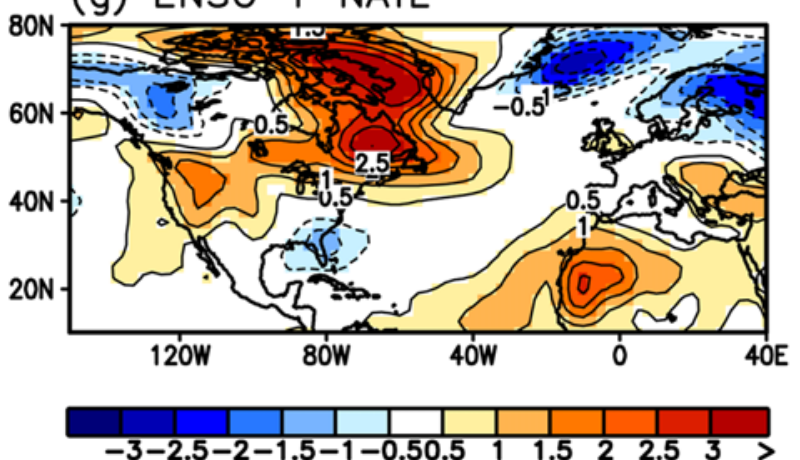

PRCP

(b) ENSO

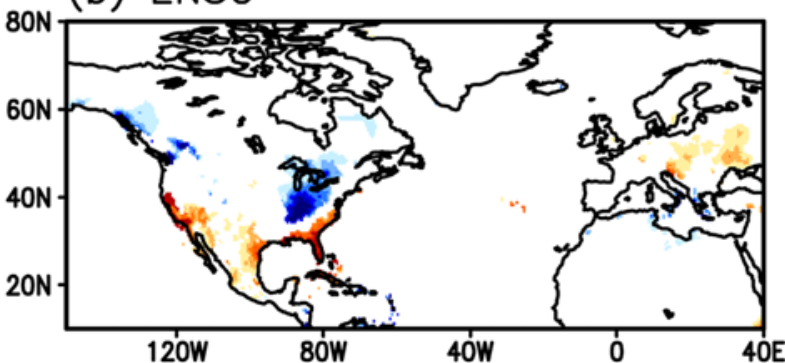

(d) ENSO only

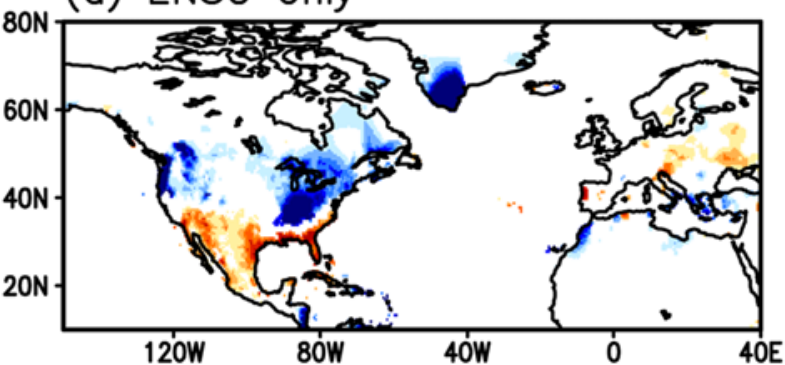

(f) NATL only

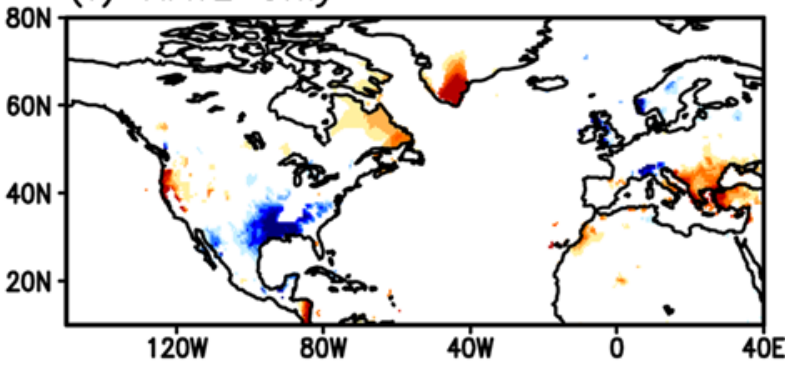

(h) ENSO + NATL

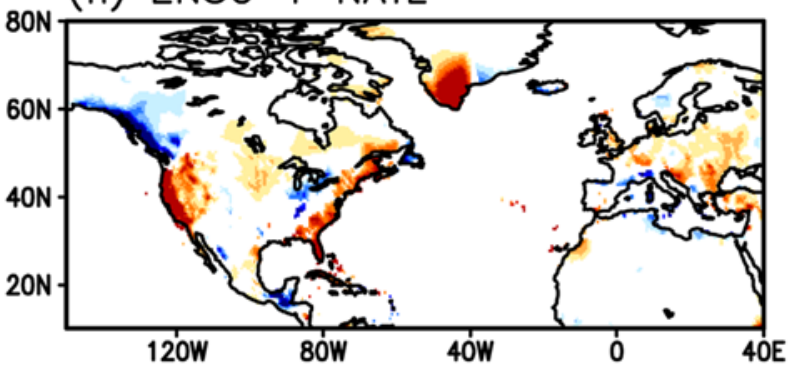

$-0.6-0.5-0.4-0.3-0.2-0.10 .10 .2 \frac{1}{0.3} \frac{1}{0.4} \frac{1}{0.5} \frac{1}{0.6}>$

Fig. 7. The surface temperature (left panel) and precipitation (right panel) composite of 'conventional ENSO', 'ENSO only', 'NATL only', and 'ENSO + NATL' cases in observations. Note that the regions where significance level is over 99\% are shaded.

modulating the global El Niño impacts.

\section{c. Statistical prediction}

So far, we showed that NATL SSTA is crucial to determine the ENSO teleconnection over the North Atlantic and Western Europe. This leads to the idea that, as well as NINO3 SST, the
NATL SSTA is a good predictor on climate variability over these regions. To show this, we perform a simple statistical simulation of JF surface temperature and precipitation using JF Nino3 and JF NATL index. Note that this is not the real 'prediction' because predictor (i.e., SST indices) does not lead the predictand (i.e., global surface temperature and precipitation). However, it can have some implications for the 
(a) Nino3 only

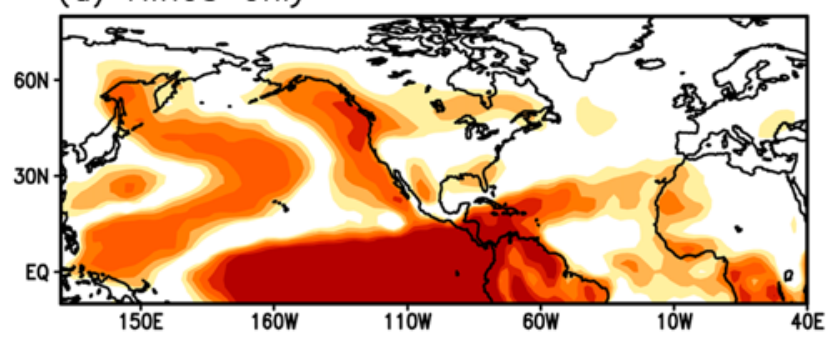

(c) Nino3 + NATL

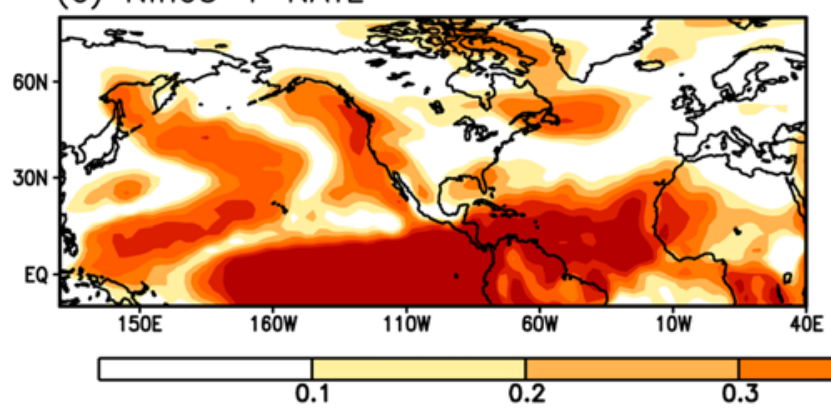

PRCP

(b) Nino3 only

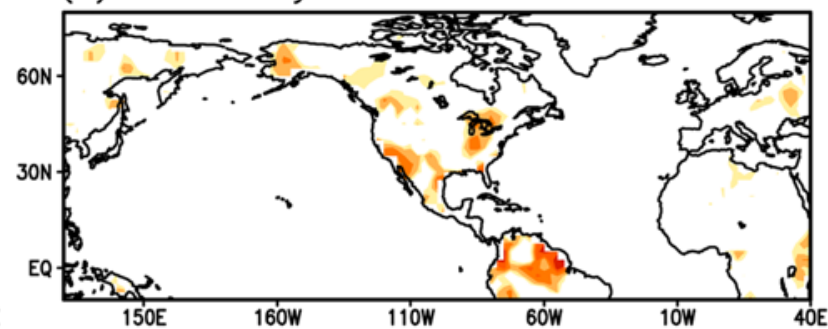

(d) NIno3 + NATL

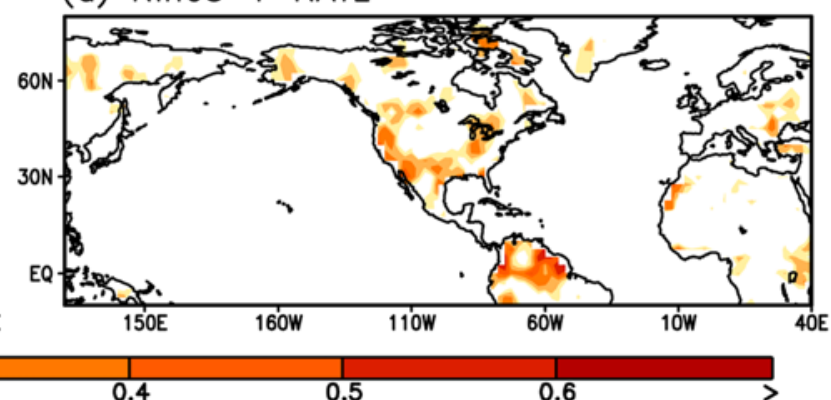

(e) $(c)-(a)$

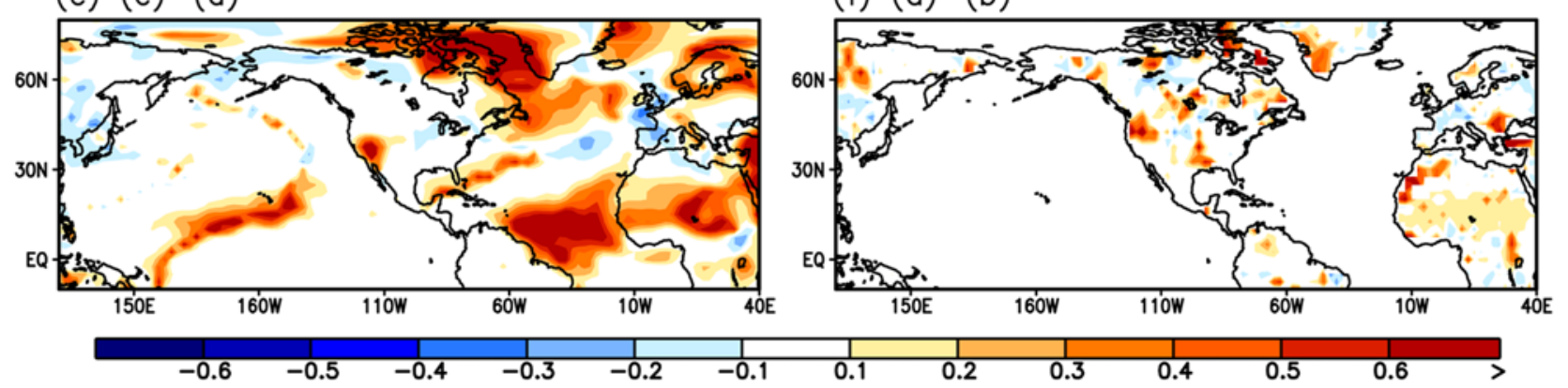

Fig. 8. The correlation skill of surface temperature (left panel) and precipitation over the land (right panel) between the observation and statistical prediction using only Nino3 (upper panel), using Nino3 and NATL index (mid panel). The lower panel shows the difference in correlation skill.

statistical correction of the CGCM predictions, because the prediction skill of Atlantic SST is significant while that of Z500 (or other atmospheric variables) over the mid- and North Atlantic is relatively low after few months (e.g., Fig. 2 of Lee et al., 2011). By comparing prediction skill only using Nino3 to that using both Nino3 and NATL index, we can show the importance of NATL SSTA to explain North Atlantic and Western Europe climate variability. To formulate the statistical relationship between the predictor (i.e., Nino3 and NATL index) and predictand (i.e., global surface temperature, and precipitation), we used multiple linear regression method (Montgomery and Peck, 1982). Note that this statistical relationship is constructed without the target year for crossvalidation, therefore, the number of sample for the statistical relationship is 59 .

Figure 8 shows the correlation skill between the observation and statistical prediction results. When the predictor is only Nino3 (Fig. 8a), the predictable signal in surface temperature is confined over the Pacific, and some area of the equatorial Atlantic. The prediction skill over the North Pacific reaches to 0.7 , and that over the off-equatorial western Atlantic at $20^{\circ} \mathrm{N}$ is about 0.6. In addition, there are weak signals over the eastern Canada. However, the climate variability over the North Atlantic and Western Europe is not predictable at all using Nino3 index. On the other hand, when both Nino3 and NATL index are used as predictor, the predictable regions are extended to North Atlantic and west of the Greenland. In surface temperature, the correlation skill over the eastern Canada and North Atlantic is between 0.4 to 0.6. Being different from the surface temperature, prediction skill of precipitation anomaly is far low whether NATL index is used or not, therefore, the differences in values between forecast using Nino3 and both Nino3 and NATL index would not be meaningful. However, just note that the correlation difference map (Fig. 8f) shows systematical improvement with NATL index over the Canada, North Atlantic, and European regions. 


\section{All Case}

(a) ENSO only

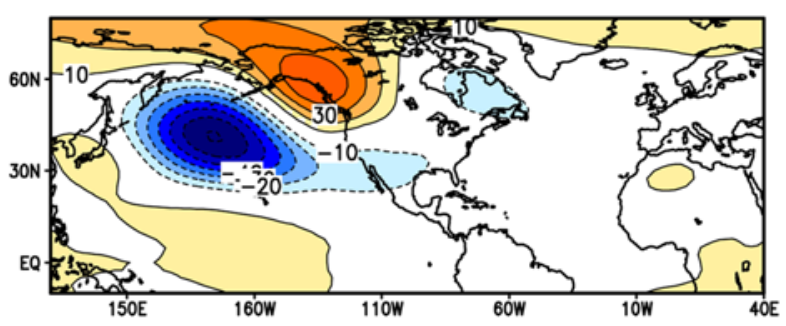

(b) ENSO + NATL

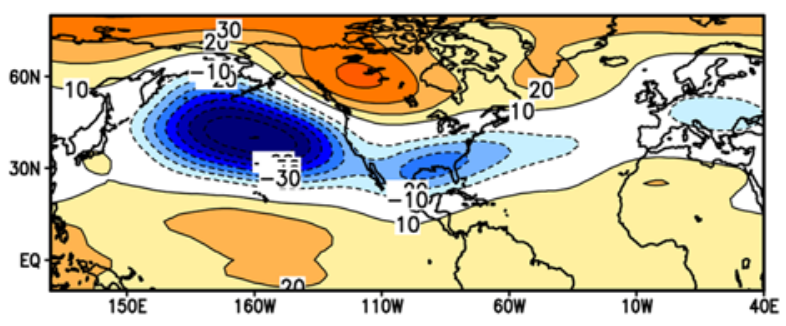

Moderate Case

(c) ENSO only

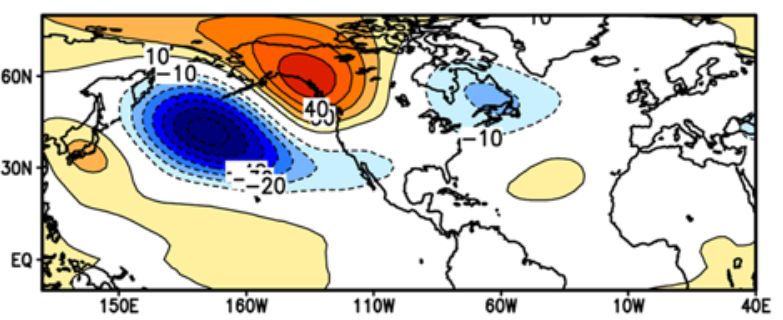

(d) ENSO + NATL

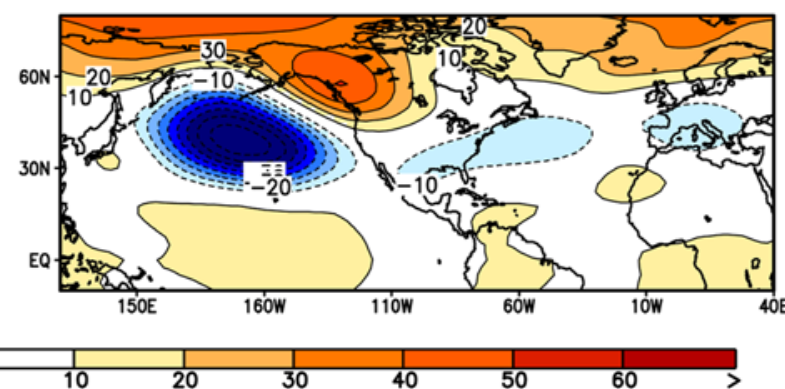

Fig. 9. The Z500 anomaly composite map of 'ENSO only' (upper panel) and 'ENSO + NATL' (lower panel) cases when Nino3 index have NATL warming (left panels) and moderate positive magnitudes (right panel, between 0.5 and 1.5 standard deviations).

All Case

(a) ENSO only

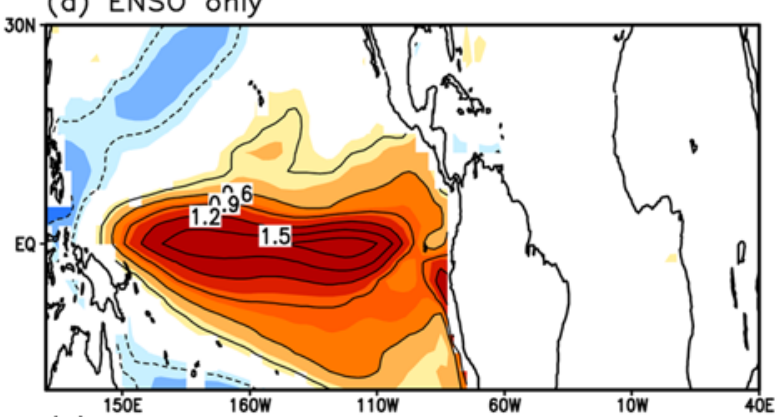

(b) $\stackrel{1500}{\text { ENSO }}+\stackrel{160 \mathrm{~N}}{\text { NATL }}$

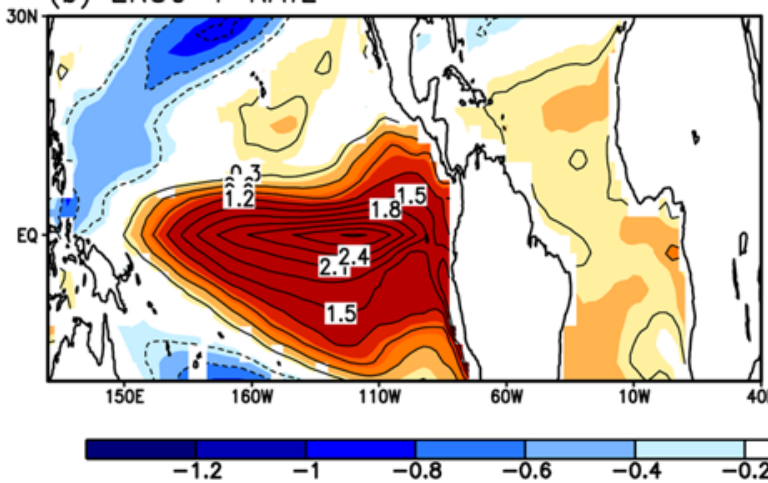

Moderate Case

(c) ENSO only

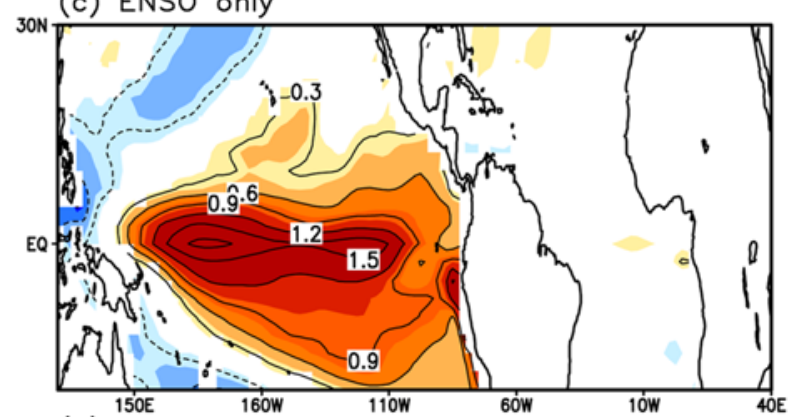

(d) ENSO + NATL

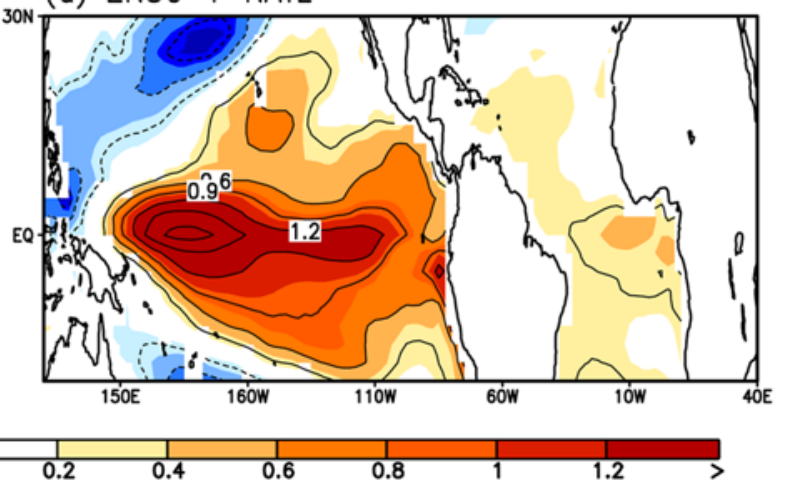

Fig. 10. Same as Fig. 9, but for SST anomalies.

\section{Coupled model results}

Until now, we analyzed observational data to yield the important role of NATL SSTA on ENSO teleconnection over the North Atlantic and European region. However, the observational data can be limited to show a robust result due to 
TS

(a) ENSO

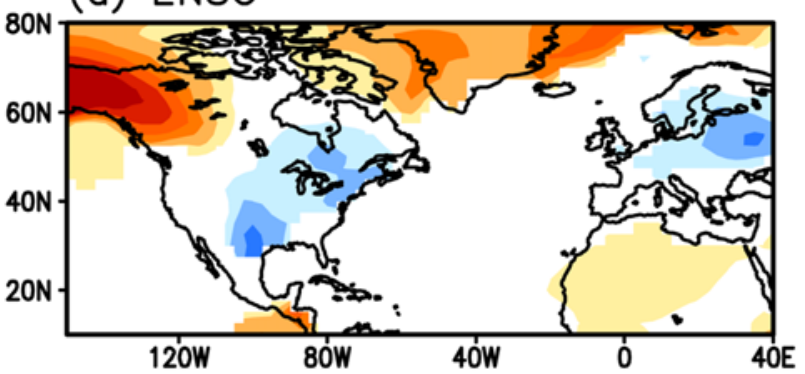

(c) ENSO only

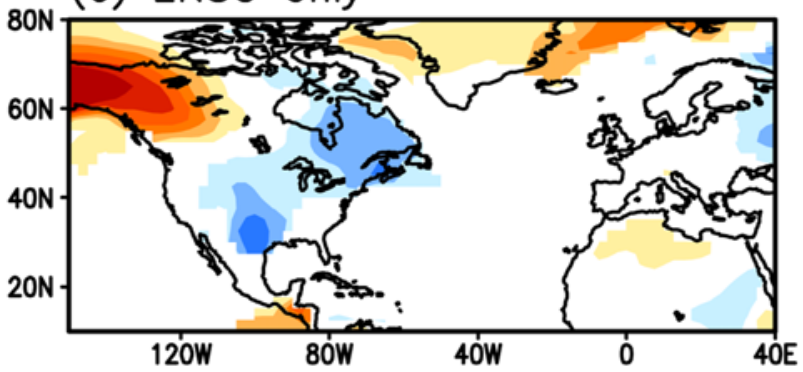

(e) NATL only

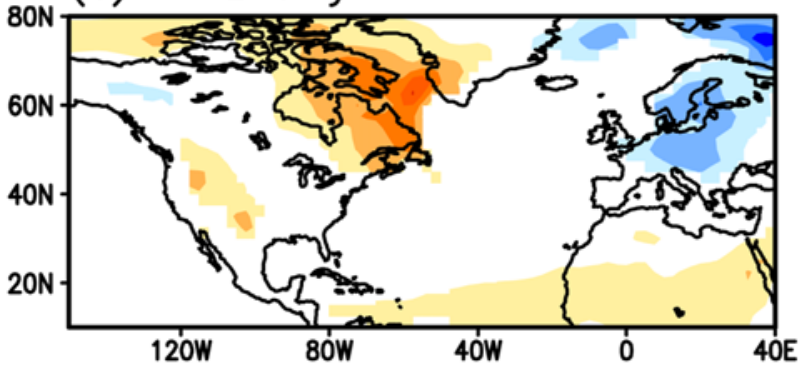

(g) ENSO + NATL

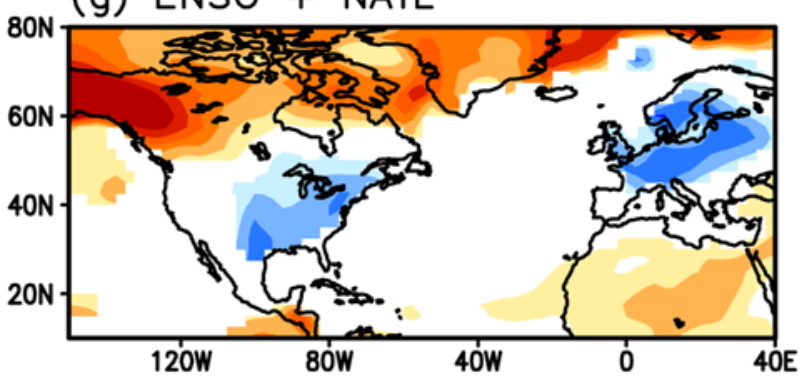

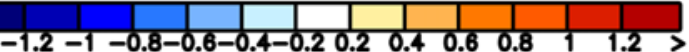

PRCP

(b) ENSO

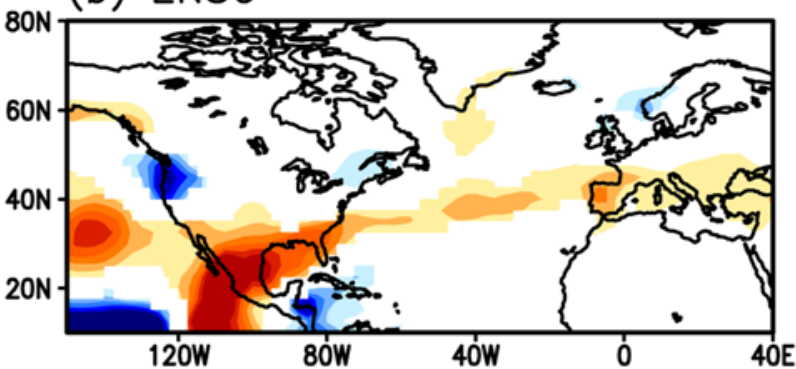

(d) ENSO only

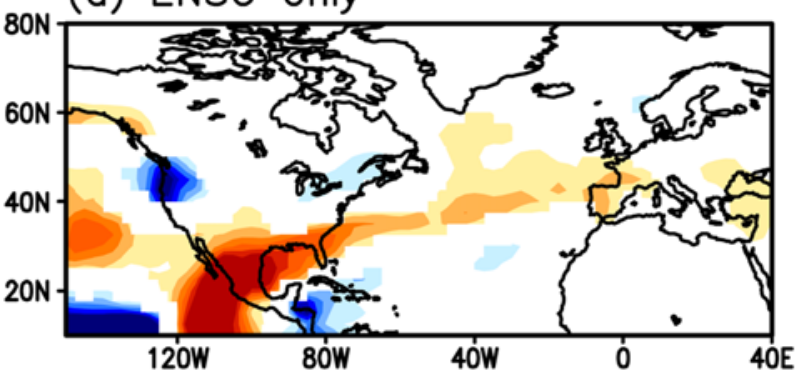

(f) NATL only

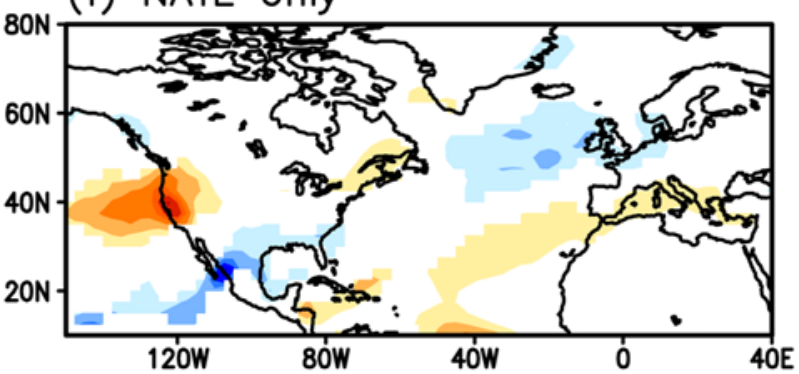

(h) ENSO + NATL

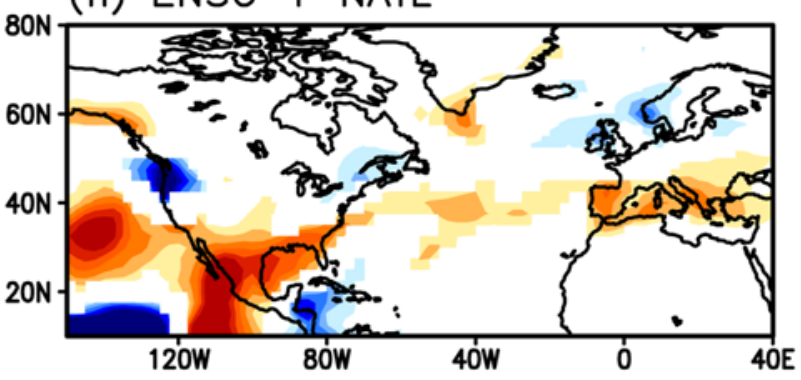

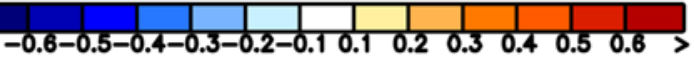

Fig. 11. The surface temperature (left panel) and precipitation (right panel) composite of 'conventional ENSO', 'ENSO only', 'NATL only', and 'ENSO + NATL' cases in the model. Note that the criteria for composites are same as the right panels of Fig. 9, and the regions where significance level is over $99 \%$ are shaded.

small samples. Therefore, we examine the impact of NATL SSTA on ENSO teleconnection in GFDL CM2.1 for more stable analysis with aids of large number of samples, which is participated in Coupled Model Intercomparison Project Phase 3 (CMIP3) archives.

The left panels of Figure 9 show the Z500 composite map at
'ENSO only' and 'ENSO + NATL' case. The criteria for each composite are the same as Fig. 5, and the number of cases is shown in Table 1. Note that the definition of the Nino3 index is same as that in the observational analysis (i.e., SSTA over 150$\left.90^{\circ} \mathrm{W}, 5^{\circ} \mathrm{S}-5^{\circ} \mathrm{N}\right)$. Consistent with the observation, the 'ENSO only' composite shows the weak Z500 anomaly over the North 
Atlantic, even though the atmospheric response over the Norwegian Sea is stronger than the observed. On the other hand, in 'ENSO + NATL' case, the Z500 response is positive over the North Atlantic, implying that the ENSO teleconnection response is quite dependent on the presence of the NATL warming. This is consistent with the observational findings that NATL warming is likely to induce the positive Z500 anomaly over the North Atlantic, and negative Z500 anomaly over the Western Europe.

To a large extent, strong ENSO events tend to accompany the NATL SSTA. Therefore, the ENSO only composite exhibits weaker SST anomalies over the tropical areas, compared to that of the 'ENSO + NATL' composite in both observation and model. As shown in Figs. 10a, b, observation shows stronger Nino3 magnitude in 'ENSO + NATL' (i.e., $1.6^{\circ} \mathrm{C}$ ) than that in 'ENSO only' (i.e., $1.2^{\circ} \mathrm{C}$ ) cases. One may argue that the differences in the teleconnection pattern between two composites as shown Figs. 5 and 9, can be resulted from the different magnitude of El Niño. Due to the large number of sample in model simulation, we can further restrict the criteria, which is a moderate ENSO (or NATL) is defined as having a magnitude of the Nino3 (or NATL) index between 0.5 and 1.5 std. This further restriction make similar magnitude of ENSO between the 'ENSO only' and 'ENSO + NATL' case, leading to a fair comparison to examine the sole impact of NATL SSTA. Note that this is also consistent with other studies that ENSO is negatively correlated with the NAO only when tropical SST anomalies are strong (Huang et al., 1998). As expected, SSTA magnitude in 'ENSO + NATL' and 'ENSO only' becomes similar (not shown). For example, the magnitude of Nino3 in 'ENSO + NATL', and 'ENSO only' is 1.20, and 1.14 (Figs. $10 \mathrm{c}, \mathrm{d})$. As shown in the right panels of Fig. 9, it is evident that the previous observational findings are still rigorous with similar Nino3 index that the simulated Z500 anomaly over the North Atlantic and Western Europe is different whether NATL warming exists or not, even though the difference becomes smaller. For example, there is a negative Z500 anomaly over the eastern Canada in 'ENSO only' case, while it is not shown in 'ENSO + NATL'. In addition, there is negative Z500 anomaly over the Western Europe in 'ENSO + NATL' case, while it is not shown in 'ENSO only' case.

In addition, as a counterpart of Fig. 7, we show in Fig. 11 the surface temperature and precipitation composite in the model simulation in moderate cases (i.e., $0.5 \mathrm{std}<$ index $<1.5 \mathrm{std}$ ). During the 'ENSO' case, there are negative surface temperature anomalies over the eastern United States and positive anomalies over Alaska. This is somewhat different from the observation, and it may be due to the positive Z500 anomaly is confined over the Alaska and shifted to the west in the model simulation. In 'ENSO only' case, the overall response is quite similar to the 'ENSO' case, except for the response over the Greenland and the Europe. It implies that the ENSO-related surface temperature response over North Atlantic and Europe is mainly determined by the NATL SSTA, which is consistent conclusion with the observational analysis. In addition, the opposite response between the 'ENSO only' and 'NATL only' cases is also clearly shown both in surface temperature and precipitation composite. For example, in the 'NATL only' case, precipitation response over the southern America is opposite to that in 'El Niño only' case.

In the 'ENSO + NATL' case, the robust difference from 'ENSO only' case is over the Greenland and the Western Europe. The positive surface temperature over the Greenland, and negative anomaly over the Western Europe is not shown at all in 'ENSO only' case, while shown in the 'NATL only' case. Similarly, the precipitation response over the Western Europe resembles the response in 'NATL only' case to some extent. It supports our previous observational findings that the NATL warming plays a significant role in modulating in the El Niño teleconnection and global impacts.

\section{Summary and discussions}

In this study, the teleconnection patterns over the North Atlantic and Europe during ENSO are investigated using observational data and a long simulation of the CGCM. It is found that teleconnection pattern over the North Atlantic regions during the El Niño significantly depends on whether El Niño is accompanied with the off-equatorial North Atlantic (NATL) SST warming. The NATL warming tends to induces positive (negative) geopotential-height anomalies over the North Atlantic (Western Europe) associated with the negative NAO-like pattern. This implies the Rossby wave propagation due to the NATL SST warming as the PNA pattern associated with the ENSO forcing, however, response to the NATL forcing is located south-north direction, while wave response linked to the PNA pattern is propagated to the north-east. This is possibly through the role of the transient eddy (Watanabe and Kimoto, 1999; Terray and Cassou, 2002; Pan, 2005). On the other hand, the ENSO teleconnection pattern associated without NATL warming is confined over the North Pacific and America. It implies that the ENSO-related atmospheric responses over the North Atlantic and Western Europe are mainly determined by the existence of NATL warming during the El Niño events. It might be the reason why the relationship between ENSO index and the North Atlantic and European climate seems to be complex, with the results depending on the data period and season as previous studies pointed out (PozoVazquez et al., 2001; Bronnimann et al., 2007).

Even though there was no clear explanations, several studies already reported a phenomenon that the North Atlantic climate variability associated with ENSO is significantly different, depending on whether ENSO-related NATL warming is induced or not. For example, to quantify the impact of ENSO SST forcing to global climate, Lau and Nath (2001) performed Tropical Ocean-Global Atmosphere (TOGA) experiment, which prescribes monthly SST variations within the tropical Pacific only, in addition to the TOGA-Mixed Layer (TOGA-ML) experiment, which is same to TOGA except that the SST conditions at all oceans were predicted using a simple ocean 
mixed layer model. Because the off-equatorial NATL warming is successfully induced in TOGA-ML experiment through airsea interaction, we can presume the impact of NATL warming by comparing atmospheric responses of two experiments. They showed that responses of TOGA-ML experiments shows south-north dipole pattern over the Atlantic, however, Z500 responses of TOGA run is quite different (see their Figs. 1012), which is consistent to our study. They argued that the difference is merely caused by the local air-sea interaction over the North Atlantic at that time, however, this study provides another interpretation that the role of NATL warming induced by Pacific SST warming can lead the differences.

One may wonder this finding is still rigorous for the Warm Pool (WP) (or central Pacific (CP))-type El Niño (Larkin and Harrison, 2005a, b; Kug et al., 2009) as some previous studies have demonstrated that the teleconnections even in the North Pacific are quite different between canonical and WP El Niño. To check this point whether the finding in this study is still rigorous for the WP El Niño, we performed the similar composite analysis as shown in Fig. 5 for WP ENSO (not shown). The WP El Niño is defined when JF Nino3 index is smaller than 0.5 standard deviation and JF Nino4 index is larger than 0.5 standard deviation, which is similar to the definition of WP El Niño in Kug et al. (2009). In 'WP ENSO + NATL' composite, even though there is difference from canonical and WP ENSO, however, the NAO-like signal structure over the Atlantic is still robust. On the other hand, this is not shown in 'WP ENSO only' composite, while wave structure propagated from the equatorial Pacific is clear. It means that the role of NATL SST to modulate ENSO teleconnection is rigorous for both types of ENSO.

In this study, we separately analyzed the influence of the tropical Pacific from that of the off-equatorial North Atlantic, and demonstrated that the impact of tropical Pacific forcing on the North Atlantic climate is considerably different to that of the off-equatorial Atlantic SST anomalies. As such, we believe that this study has laid the foundation for an improved understanding of the mechanisms by which SST forcing over the tropical Pacific, and the off-equatorial North Atlantic impacts climate variability of the North Atlantic and European region during ENSO.

Acknowledgments. YGH was funded by the Korea Meteorological Administration Research and Development Program under Grant CATER 2013-3142. JSK was supported by the National Research Foundation of Korea Grant Funded by Korean Government (MEST) (NRF-2009-C1AAA001-20090093).

\section{Edited by: Tianjun Zhou}

\section{REFERENCES}

Alexander, M. A., 1990: Simulation of the response of the North Pacific Ocean to the anomalous atmospheric circulation associated with El Niño. Clim. Dynam., 5, 53-65. 1992a: Midlatitude atmosphere-ocean interaction during El Niño. Part I: The North Pacific Ocean. J. Climate, 5, 944-958.

1992b: Midlatitude atmosphere-ocean interaction during El Niño. Part II: The North Hemisphere atmosphere. J. Climate, 5, 959-972. and J. D. Scott, 2002: The influence of ENSO on air-sea interaction in the Atlantic, Geophys. Res. Lett. 29, doi: 10.1029/2001 GL014347.

An, S.-I., J.-S. Kug, A. Timmermann, I.-S. Kang, and O. Timm, 2007: The influence of ENSO on the generation of decadal variability in the North Pacific. J. Climate, 20, 667-680.

Barnett, T. P., 1985: Variations in Near-Global Sea Level Pressure. J. Atmos. Sci., 42, 478-501.

Bronnimann, S., E. Xoplaki, C. Casty, A. Pauling, and J. Luterbacher, 2007: ENSO influence on Europe during the last centuries. Clim. Dynam., 28, 181-197.

Chang, P., Y. Fang, R. Saravanan, L. Ji, and H. Seidel, 2006: The cause of the fragile relationship between the Pacific El Niño and the Atlantic Nino. Nature, 443, 324-328.

Chiang, J. C. H, and A. H. Sobel, 2002: Tropical tropospheric temperature variations caused by ENSO and their influence on the remote tropical climate. J. Climate, 15, 2616-2631.

and B. R. Lintner, 2005: Mechanisms of remote tropical surface warming during El Niño. J. Climate, 18, 4130-4149.

Cohen, J., and P. Cohen, 1983: Applied multi regression/correlation analysis for the behavioral sciences. Lawrence Erlbam Associate, 545 pp.

Curtis C., and S. Hastenrath, 1995: Forcing of anomalous sea surface temperature evolution in the tropical Atlantic during Pacific warm events. J. Geophys. Res-Oceans., 100, 15835-15847.

Czaja, A., P. van der Vaart, and J. Marshall, 2002: A diagnostic study of the role of remote forcing in tropical Atlantic variability. J. Climate, 15, 3280-3290.

Delworth, T. L., A. J. Broccoli, A. Rosati, R. J. Stouffer, V. Balaji, J. A. Beesley, and R. Zhang, 2006: GFDL's CM2 global coupled climate models. Part I: Formulation and simulation characteristics. J. Climate, 19, 634-674.

Enfield, D. B., 1996: Relationships of inter-american rainfall to tropical Atlantic and Pacific SST variability. Geophys. Res. Lett., 23, $3305-$ 3308 .

, and D. A. Mayer, 1997: Tropical Atlantic sea surface temperature variability and its relation to El Niño-Southern Oscillation. J. Geophys. Res., 102, 929-945.

Fraedrich, K., 1990: European gross wetter during the warm and cold extremes of the El Niñco/Southern Oscillation. Int. J. Climatol., 10, 2131.

Frankignoul, C., and K. Hasselmann, 1977: Stochastic climate models, part II: application to sea-surface temperature variability and thermocline variability. Tellus, 29, 289-305.

Halpert, M. S., and C. F. Ropelewski, 1992: Surface temperature patterns associated with the Southern Oscillation. J. Climate, 5, 577-593.

Held, I. M., and I. -S. Kang, 1987: Barotropic models of the extratropical responses to El Niño. J. Atmos. Sci., 44, 3576-3586.

Horel, J. D., and J. M. Wallace, 1981: Planetary-scale atmospheric phenomena associated with the Southern Oscillation. Mon. Wea. Rev, 109, 813-829.

Hoskins, B. J., and D. J. Karoly, 1981: The steady linear response of a spherical atmosphere to thermal and orographic forcing. J. Atmos. Sci., 38, 1179-1196.

Huang J., H. Higuchi, and A. Shabbar, 1998: The relationship between the North Atlantic oscillation and El Niño -southern oscillation. Geophys. Res. Lett., 25, 2707-2710.

Kalnay E., and Coauthors, 1996: The NCEP/NCAR 40-Year Reanalysis Project. Bull. Amer. Meteor. Soc., 77, 437-471. 
Kiladis, G. N., and H. F. Diaz, 1989: Global climatic anomalies associated with extremes of the Southern Oscillation. J. Climate, 2, 1069-1090.

Kitoh, A., H. Koide, K. Kodera, S. Yukimoto, and A. Noda, 1996: Interannual variability in the stratospheric-tropospheric circulation in a coupled ocean-atmosphere GCM. Geophys. Res. Lett., 23, 543-546.

Klein, S. A., B. J. Soden, and N.-C. Lau, 1999: Remote sea surface temperature variations during ENSO: Evidence for a tropical atmospheric bridge. J. Climate, 12, 917-932.

Kug, J.-S., and I.-S. Kang, 2006: Interactive feedback between the Indian Ocean and ENSO. J. Climate, 19, 1784-1801.

, F. F. Jin, and S.-I. An, 2009: Two types of El Niño events: cold tongue El Niño and warm pool El Niño. J. Climate, 22, 1499-1515. , and 2009: Left-hand rule for synoptic eddy feedback on low-frequency flow. Geophys. Res. Lett., 36, L05709, doi:10.1029/2008 GL036435.

, J. Choi, S.-I. An, F.-F. Jin, and A. T. Wittenberg, 2010a: Warm pool and cold tongue El Niño events as simulated by the GFDL 2.1 coupled GCM. J. Climate, 23, 1226-1239.

, F.-F. Jin, J.-H. Park, H.-L. Ren, and I. -S. Kang, 2010b: A general rule for synoptic-eddy feedback onto the low-frequency flow. Clim. Dynam., 35, doi: 10.1007/s00382-009-0606-8.

Larkin, N., and D. Harrison, 2005a: On the definition of El Niño and associated seasonal average US weather anomalies. Geophys. Res. Lett., 32, L13705.

,2005b: Global seasonal temperature and precipitation anomalies during El Niño autumn and winter. Geophys. Res. Lett., 32, L16705.

Lau, N.-C., and M. J. Nath, 1996: The role of the "atmospheric bridge" in linking tropical Pacific ENSO events to extratropical SST anomalies. $J$. Climate, 9, 2036-2057.

, and 2001: Impact of ENSO on SST variability in the North Pacific and North Atlantic: Seasonal dependence and role of extratropical air-sea coupling. J. Climate, 14, 2846-2866.

Lee, J.-Y., B. Wang, Q. Ding, K.-J. Ha, J.-B. Ahn, A. Kumar, B. Stern, and O. Alves, 2011: How predictable is the Northern Hemisphere summer upper-tropospheric circulation?. Clim. Dynam., 37, 1189-1203.

Lin, S.-J., 2004: A“vertically Lagrangian" finite-volume dynamical core for global models. Mon. Wea. Rev., 132, 2293-2307.

Moura, A. D., and J. Shukla., 1981: On the dynamics of droughts in northeast Brazil: Observation, theory and numerical experiments with a general circulation model. J. Atmos. Sci., 38, 2653-2675.

Montgomery, D. C., and E. A. Peck, 1982: Introduction to Linear Regression Analysis., John Wiley and Sons, New York, p. 279.

Montroy, D. L., 1997: Linear relation of central and eastern North American precipitation to tropical Pacific sea surface temperature anomalies. J. Climate. 10, 541-558.

, M. B. Richman, and P. J. Lamb, 1998: Observed nonlinearities of monthly teleconnections between tropical Pacific sea surface temperature anomalies and central and eastern North American precipitation. $J$. Climate., 11, 1812-1835.

Moron, V., and I. Gouirand, 2003: Seasonal modulation of the El Niño southern oscillation relationship with sea level pressure anomalies over the North Atlantic in October-March 1873-1996. Int. J. Climatol., 23, 143-155.

Okumura, Y., S.-P. Xie, A. Numaguti, and Y. Tanimoto, 2001: Tropical Atlantic air-sea interaction and its influence on the NAO. Geophys. Res. Lett., 28, 1507-1510.

Osborn, T. J., K. R. Briffa, S. F. B. Tett, P. D. Jones, and R. M. Trigo, 1999: Evaluation of the North Atlantic oscillation as simulated by a climate model. Clim. Dynam., 15, 685-702.

Pan, L., 2005: Observed positive feedback between the NAO and the North Atlantic SSTA tripole. Geophys. Res. Lett., 32, L06707.

Peng, S., W. A. Robinson, and S. Li, 2003: Mechanisms for the NAO responses to the North Atlantic SST tripole. J. Climate, 16, 1987-2004.
Pozo-Vázquez, D., M. J. Esteban-Parra, F. S. Rodrigo, and Y. Castro-Díez, 2001: The Association between ENSO and winter atmospheric circulation and temperature in the North Atlantic region. J. Climate, 14, 3408-3420.

Rasmussen, E. M., and T. H. Carpenter, 1982: Variations in tropical sea surface temperature and surface wind fields associated with the Southern Oscillation/El Niño. Mon. Wea. Rev., 110, 354-384.

Ren, H.-L., F.-F. Jin, J.-S. Kug, J. Zhao, and J.-H. Park, 2009: A kinematic mechanism for positive feedback between synoptic eddies and NAO. Geophys. Res. Lett., 36, doi:10.1029/2009GL037294.

Rodwell, M. J., D. P. Rowell, and C. K. Folland, 1999: Oceanic forcing of the wintertime North Atlantic Oscillation and European climate. Nature, 398, 320-323.

Robertson, A. W., C. R. Mechoso, and Y. J. Kim, 2000: The influence of Atlantic sea surface temperature anomalies on the North Atlantic Oscillation. J. Climate, 13, 122-138.

Rodriguez-Fonseca, B., I. Polo, J. García-Serrano, T. Losada, E. Mohino, C. R. Mechoso, and F. Kucharski, 2009: Are Atlantic Niños enhancing Pacific ENSO events in recent decades?. Geophys. Res. Lett., 36, doi:10.1029/2009GL040048.

Rogers, J. C., 1984: 'The association between the North Atlantic Oscillation and the Southern Oscillation in the Northern Hemisphere'. Mon. Wea. Rev. 112, 1999-2015.

Ropelewski, C. F., and M. S. Halpert, 1987: Global and regional scale precipitation patterns associated with the El Niño/Southern Oscillation cycle. Mon. Wea. Rev., 115, 1606-1626.

, and _ 1989: Precipitation patterns associated with the high index phase of the Southern Oscillation. J. Climate, 2, 268-284.

Saravanan, R., and P. Chang, 2000: Interaction between tropical Atlantic variability and El Niño-Southern Oscillation. J. Climate, 13, 2177-2194.

Servain, J., and D. M. Leglet, 1986: Empirical orthogonal function analysis of tropical Atlantic sea surface temperature and wind stress. J. Geophys. Res., 91, 14,181-14,191.

1991: Simple climatic indices for the tropical atlantic ocean and some applications. J. Geophys. Res., 96, 15,137-15,146.

Siegfried, S., and Coauthors, 2009: A US CLIVAR project to assess and compare the responses of global climate models to drought-related SST forcing patterns: overview and results. J. Climate. 22, 5251-5272.

Smith, T. M., and R. W. Reynolds, 2004: Improved extended reconstruction of SST (1854-1997). J. Climate, 18, 2466-2477.

Sutton, R. T., W. A. Norton, and S. P. Jewson, 2001: The North Atlantic Oscillation - What role for the Ocean?. Atmos. Sci. Lett., 1, 89-100, doi: 10.1006/asle.2000.0018.

Terray, L., and C. Cassou, 2002: Tropical Atlantic sea surface temperature forcing of quasi-decadal climate variability over the North AtlanticEuropean region. J. Climate, 15, 3170-3187.

Trenberth, K. E., and J. W. Hurrell, 1994: Decadal atmosphere-ocean variations in the Pacific. Clim. Dynam., 9, 303-319.

, G. W. Branstator, D. Karoly, A. Kumar, N. -C. Lau, and C. Ropelewski, 1998: Progress during TOGA in understanding and modeling global teleconnections associated with tropical sea surface temperatures. J. Geophys. Res., 103, 14,291-14,324.

van Loon, H., and R. A. Madden, 1981: The Southern Oscillation. Part I: Global associations with pressure and temperature in Northern Winter. Mon. Wea. Rev., 109, 1150-1162.

van Oldenborgh, G. J., G. Burgers, and A. K. Tank, 2000: On the El Niño teleconnection to spring precipitation in Europe. Int. J. Climatol., 20, 565-574.

Walker, G. T., and E. W. Bliss, 1932: World weather V., Memoirs of the Royal Meteorological Society, 4, 53-84.

Wang, B., R. Wu, and X. Fu, 2000: Pacific-East Asian teleconnection: How does ENSO affect east Asian climate. J. Climate, 13, 1517-1536.

Wang, C., S.-K. Lee, and C. R. Mechoso, 2010: Interhemispheric Influence 
of the Atlantic Warm Pool on the Southeastern Pacific. J. Climate, 23, 404-418.

Wang, X., C. Wang, W. Zhou, D. Wang, and J. Son, 2011: Teleconnected influence of North Atlantic sea surface temperature on the El Niño onset. Clim. Dynam., 37, 663-676.

Watanabe, M., and M. Kimoto, 1999: Tropical-extratropical connection in the Atlantic atomosphere-ocean variability. Geophys. Res. Lett., 26,
2247-2250.

Wittenberg, A. T., A. Rosati, N. -C. Lau, and J. J. Ploshay, 2006: GFDL's CM2 global coupled climate models. Part III: Tropical Pacific climate and ENSO. J. Climate, 19, 698-722.

Wu L., and Z. Liu, 2002: Is Tropical Atlantic variability driven by the North Atlantic Oscillation?. Geophys. Res. Lett. 29, doi: 10.1029/2002 GL014939. 